\title{
THE SYNDROMES OF CORRECTED TRANSPOSITION OF THE GREAT VESSELS
}

\author{
BY \\ REDA M. SHAHER \\ From the Cardiac Department, Guy's Hospital, London \\ Received October 23, 1962
}

In 1875 Rokitansky first described corrected transposition of the great vessels. Harris and Farber (1939) and Cardell (1956) thought that since inversion might occur in any part of the cardiac tube, in theory any one of eight types of transposition could result (Fig. 1). In their groups A3 and A4 the aorta arises from the morphological left ventricle but receives unoxygenated blood, hence they regarded it as being "corrected" anatomically but not physiologically. Their groups B1 and B2 associated with bulbus inversion, and sinu-atrial and ventricular inversion respectively, show both physiological and anatomical correction, the aorta arising from the morphological left ventricle and receiving oxygenated blood. In B3 and B4 associated with bulbo-ventricular inversion, and sinu-atrial inversion respectively, the aorta arises from the morphological right ventricle but receives oxygenated blood, hence it is corrected physiologically but not anatomically. Cardell (1956) and Harley (1958) suggested that the term corrected transposition should be confined to those cases with physiological correction only. Recent papers on the subject tend to confine the words "corrected transposition" to one anatomical type, i.e. the one associated with bulbo-ventricular inversion (Cardell's B3). Several papers have included cases of single ventricle among their material. The presence of a single ventricle vitiates any discussion of whether the transposition present is corrected or not, since mixing of the arterial and venous blood occurs in the common chamber. Several definitions have been given for corrected transposition, but we propose to use the term simply to define the condition where the transposed aorta receives oxygenated blood, and the transposed pulmonary artery receives venous blood.

This paper is presented to describe three different types of corrected transposition that are readily recognizable whether there is lævocardia or dextrocardia. Inversion means a reversal of the lateral relation between structures in the frontal plane. Complete transposition of the great vessels means that the aorta is lying anterior and to the right of the pulmonary artery, with lævocardia. Inverted transposition of the great vessels is used in the sense of Spitzer (1923) where the aorta is lying anterior and to the left of the pulmonary artery, with lævocardia. During the course of the discussion cases of dextrocardia and lævocardia will be mentioned. In order that these anomalies shall be properly understood, there should be a frame of reference which is that of normality, to which the abnormal situation may be compared in terms of inversion or transposition. The normal dextroposed heart in dextrocardia with situs inversus, with the venous chambers to the patient's left, is a mirror image of the normal lævoposed heart in situs solitus. If in dextrocardia, the venous atrium is on the patient's right and the arterial on the left, they are by our definition inverted. This point is emphasized because this definition differs from that of Mandelstamm and Reinberg (1928), Burchell and Pugh (1952), Keith, Rowe, and Vlad (1958), Grant (1958), De La Cruz et al. (1959) and others, who describe a heart situated in the right side of the chest with its venous chambers on the right, as having normal relation of the cardiac chambers. This type of 

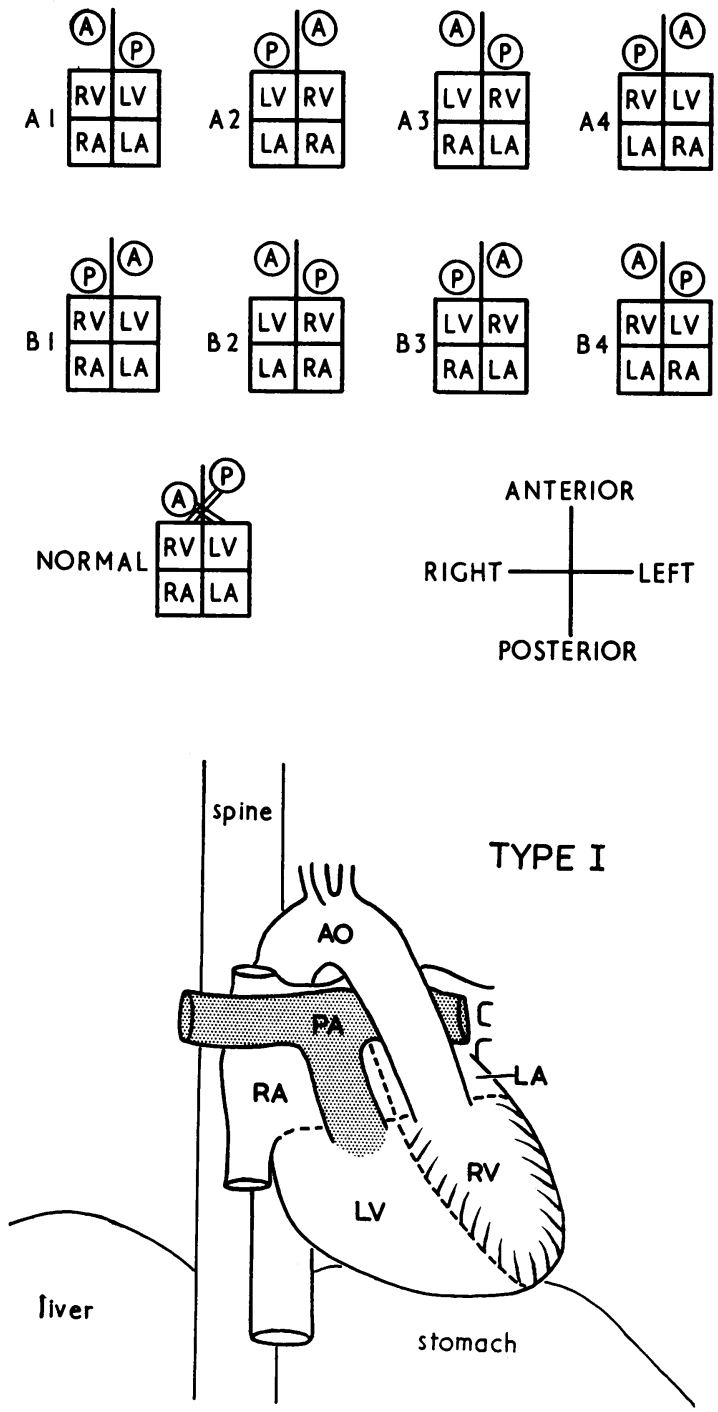

Fig. 2.-Corrected transposition type 1. AO=aorta, PA = pulmonary artery. LA, RA, LV, and RV indicate the morphological left and right atria and ventricles respectively. Only ventricles inverted.
Fig. 1.-Diagram illustrating the various types of transposition of the great vessels with lævocardia. A similar diagram of a normal heart is included for the purposes of orientation. A, indicates the aorta; $P$, the pulmonary trunk; LA, LV, RA, and RV, indicate the morphological left or right atrium or ventricle. A1 shows complete transposition with situs solitus of the atria and the ventricles; A2 shows inverted transposition with atrioventricular inversion; A3 shows complete transposition with ventricular inversion; A4 shows inverted transposition with sinu-atrial inversion; B1 shows bulbus inversion (inverted transposition with situs solitus of the atria and the ventricles); B2 shows complete transposition with sinu-atrial and ventricular inversion; B3 shows bulbo-ventricular inversion (inverted transposition with ventricular inversion); B4 shows complete transposition with sinoatrial inversion (modified from Cardell, 1956, after Harris and Farber, 1939).

definition serves to create confusion in an already complicated situation, since two separate embryological explanations would have to be given for mirror image lesions occurring in lævocardia and dextrocardia. For similar reasons, to make cases of isolated dextrocardia and lævocardia comparable from an electrocardiographic point of view, the right and left arm lead connexions should be reversed in cases of dextrocardia.

\section{SubJeCts}

Twelve patients with corrected transposition of the great vessels were seen in Guy's Hospital and one in Southampton Chest Hospital. Eleven were male and two were female and the ages ranged from 3 years to 22 years. The diagnosis was confirmed by operation in two, by angiography in nine, and by necropsy in the remaining two. Cases were divided into three types: type 1 with bulbo-ventricular inversion (8 patients); type 2 with sinu-atrial and ventricular inversion (4 patients); type 3 with sinu-atrial inversion (1 patient).

As we have excluded all cases of single ventricle, ten patients with inverted transposition were excluded from type 1 , and one patient with associated sinu-atrial inversion was also excluded. In the presence of single ventricle it is not possible to differentiate between types 2 and 3 .

\section{Anatomy AND CASE RePorts}

Type 1 Corrected Transposition (transposition with bulbo-ventricular inversion, Cardell's B3), 8 patients Fig. 2).

This type has been fully described (Walmsley, 1931; Harris and Farber, 1939; Liebow and McFarland, 1941 ; Anderson, Lillehei, and Lester, 1957; Schaefer and Rudolph, 1957; Fink et al., 1958; Kernen, 1958; Gasul, Graettinger, and Bucheleres, 1959; De La Cruz et al., 1959; De La Cruz, Polansky, and NovarroLópez, 1962; Malers et al., 1960; and Beck et al., 1961), but for purposes of comparison will be briefly reviewed here. Our patients 1-8 belong to this type but case histories will not be given in this type of 
corrected transposition. The description that follows assumes lævocardia, but will apply also to dextrocardia if the sides are reversed. The venous atrium is situated on the right. It communicates through a bicuspid right atrioventricular valve with the right-sided but morphologically left ventricle. This ventricle gives rise to the pulmonary trunk which is situated posteriorly and to the right. The arterial atrium is situated on the left, communicates through a tricuspid left atrioventricular valve with the left-sided but morphologically right ventricle. This gives rise to the aorta which is situated anteriorly and to the left. Consequently the ascending aorta takes a position normally occupied by the main pulmonary trunk at the left cardiac border. The coronary arteries are usually transposed and inverted. The left coronary artery arises from an anterior sinus and courses to the right, dividing into an anterior descending and right circumflex branches. The right coronary artery arises from a posterior sinus, courses to the left, giving a posterior descending and a left marginal branch. The left atrioventricular valve is frequently

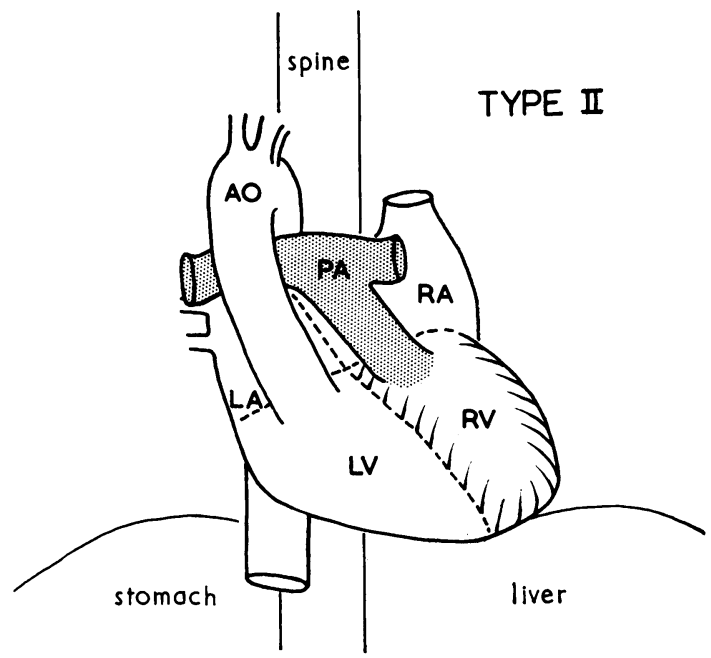

FIG. 3.-Corrected transposition type 2. Abbreviations as in Fig. 2. Abdominal viscera atria, and ventricles inverted, but not the position of the heart. incompetent and this has been attributed to anomalous insertion of the chordæ tendenæ or to an "Ebstein" type of malformation of this valve (Helmholz, Daugherty, and Edwards, 1956; Malers et al., 1960). Since the atria are not inverted the $P$ wave in lead $I$ of the electrocardiogram is usually upright. Variable grades of heart block have been described in some of these patients, the ætiology of which was thought by Anderson et al. (1957) and Beck et al. (1961), to be related to the longer and anomalous pattern of the bundle of His. In patients with complete heart block, where dissection of the bundle of His was done at necropsy, dense fibrosis was found surrounding and infiltrating the bundle, as in Walmsley's case (1931), and the patient of Carns, Ritchie, and Musser (1941). Associated lesions are frequent, the commonest of these being ventricular septal defect.

Type 2 Corrected Transposition of the Great Vessels (transposition with sinu-atrial and ventricular inversion, Cardell's B2), 4 patients (Fig. 3).

As far as we can tell this syndrome occurs only in association with isolated dextrocardia or isolated lævocardia. It has been shown elsewhere (Shaher and Johnson, 1963) that the lesions that occur with isolated dextrocardia are the mirror image of those that occur with isolated lævocardia. The description that follows assumes lævocardia but will also apply to dextrocardia if the sides are reversed. A left-sided superior vena cava and a left-sided inferior vena cava drain into a venous atrium on the left, which has a limbus and fossa ovalis on its septal surface. Through a left-sided tricuspid atrioventricular valve, blood enters a left-sided morphological right ventricle. This ventricle gives rise to a pulmonary trunk situated posteriorly and to the left. Pulmonary venous blood returns to an arterial atrium on the right which has on its septal surface the irregular configuration of the septum primum, as it is adherent to the septum secondum. Through a bicuspid atrioventricular valve, blood enters the right-sided morphological left ventricle. The aorta arises from this ventricle anteriorly and to the right. The aorta, therefore, will not form a long convexity on the left cardiac border, as in type 1. The two ventricles may lie side by side, or the morphological right ventricle may be posterior and to the left and the morphological left ventricle anterior and to the right. In all our patients and the patients studied and reported by others, the aortic arch has been on the side opposite to the cardiac apex. The coronary arteries are transposed and inverted. The left coronary artery arises from an anterior aortic sinus, courses to the right, dividing into an anterior descending and a right circumflex branch. The right coronary artery arises from a posterior sinus, courses to the left giving rise to a posterior descending and a left marginal branch. Atrioventricular block is not a common feature of this syndrome: presumably this is due to the fact that in this group correction is achieved by inversion of the atria and ventricles, so that there is no distortion of the atrioventricular region of the heart (Shaher, 1963). Owing to the presence of atrial inversion, the electrocardiogram usually shows an inverted $P$ wave in lead $\mathrm{I}$. 
Our patients 9-12 have been shown to satisfy this description. Patients 9-11 have been previously described from this hospital by Campbell and Forgacs (1953) and Campbell (1960). Patient 12 with isolated dextrocardia is described for the first time.

Patient 9. Isolated lævocardia. A boy, aged 3 years, was Case 1 of Campbell and Forgacs (1953). The electrocardiogram showed an inverted $P$ wave in lead $I$. At necropsy the superior vena cava and inferior vena cava were both on the left and each entered a left venous atrium. The atrial septum showed only a slit patency. The left atrioventricular valve was tricuspid and the large venous ventricle lay posteriorly and on the left, its outflow tract passing to the pulmonary trunk which arose behind and to the left of the aorta and overrode a high ventricular septal defect. The arterial atrium receiving the pulmonary veins was small and was situated posteriorly and to the right. The right atrioventricular valve was bicuspid and the arterial ventricle, smaller than the other, also lay on the right. The aorta arose to the extreme right of the pulmonary artery to form a right-sided arch.

Patient 10. Isolated lævocardia. A man aged 22 years was Case 3 of Campbell and Forgacs (1953) and Campbell (1960). The electrocardiogram showed an inverted P wave in lead I. At necropsy, the superior vena cava and inferior vena cava were both on the left side and entered a left-sided venous atrium. There was a large atrial septal defect. The left atrioventricular valve was tricuspid and the small venous ventricle lay posteriorly and to the left. Its outflow tract, which was obstructed by a partially encircling ridge and old vegetations, gave rise to the pulmonary artery which was severely stenosed. There was a ventricular septal defect measuring $1.4 \times 0.6 \mathrm{~cm}$. The larger arterial atrium was right sided and received the pulmonary veins. The right atrioventricular valve was bicuspid and the arterial ventricle, larger than the venous one, occupied nearly all the anterior aspect of the heart. The aorta arose from this ventricle. The great vessels were transposed (Campbell, 1962, personal communication) and the aortic arch was right sided.

Patient 11. Isolated lævocardia. A girl, aged 14 years, was briefly discussed at the age of 4 years by Campbell and Forgacs (1953). The electrocardiogram showed an inverted P wave in lead I. Radiograph of the chest showed a right-sided aortic arch. The angiocardiogram demonstrated a left-sided superior vena cava and inferior vena cava draining into a left-sided venous atrium. A venous ventricle situated on the left with an outflow tract and heavy trabeculation was opacified. The pulmonary artery arose from this ventricle (Fig. 4). It was situated posteriorly and to the left. After passage through the lungs, the dye

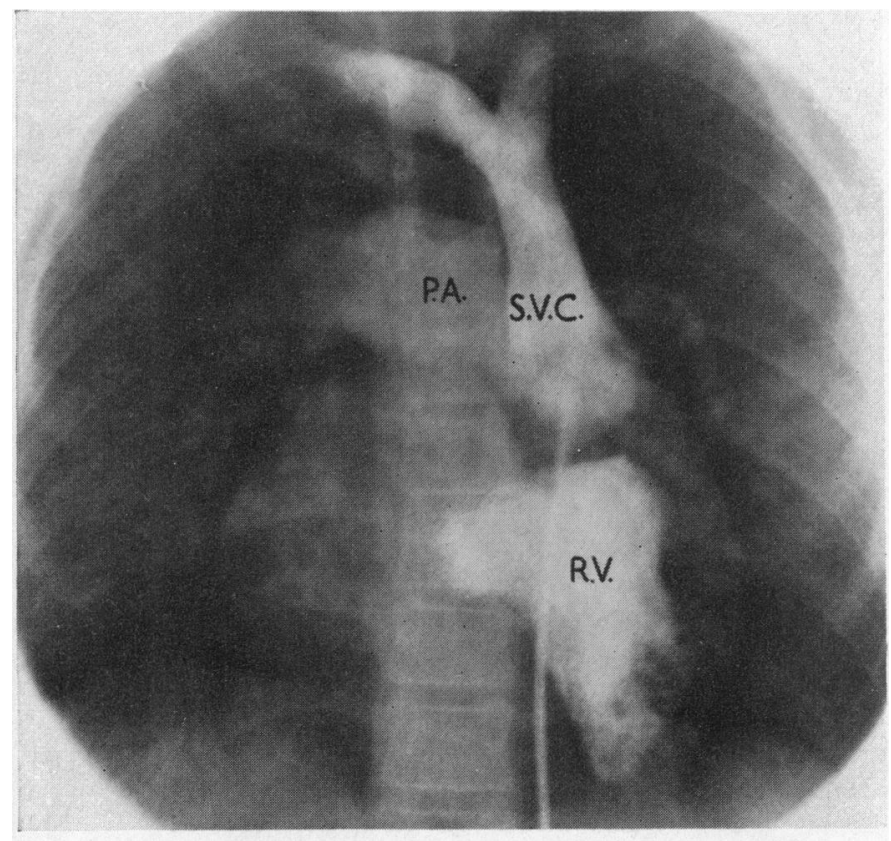

FIG. 4.-Patient 11. Venous angiocardiography showing a left superior vena cava (S.V.C.), and a left-sided venous ventricle (R.V.) with heavy trabeculations and an outflow tract, giving rise to the pulmonary artery (P.A.). 
outlined a right-sided ventricle with a smooth outline. The aorta arose from this ventricle anterior and to the right of the pulmonary artery. The aortic arch was right sided.

Patient 12. Isolated dextrocardia. A boy, aged 8 years, had been known to have congenital heart disease from early infancy. On examination, there was rather a high colour without obvious cyanosis. The first heart sound was normal and the second sound was single. There was a systolic murmur heard all over the præcordium. An electrocardiogram taken with the right and left arm leads reversed showed an inverted $P$ wave in lead I. Chest radiograph showed the heart situated on the right with a left-sided aortic arch, with normal lung fields and the stomach air bubble on the left. Right heart catheterization demonstrated a right superior vena cava, a right-sided venous atrium, and a left-sided arterial atrium. The pulmonary artery was not entered, but the right ventricular pressure was $100 / 0$ and the systemic arterial pressure was $100 / 50 \mathrm{~mm}$. Hg. Venous angiography demonstrated a right inferior vena cava draining into a right-sided venous atrium. A ventricle situated on the right with an irregular outline and an outflow tract filled next. This ventricle gave rise to the pulmonary artery which was situated posteriorly and to the right. There was pulmonary valve stenosis. An arterial ventricle with a smooth outline and situated on the left opacified through a ventricular septal defect. This ventricle gave rise to the aorta which was situated anteriorly and to the left. The aortic arch was on the left. The two ventricles lay side by side (Fig. 5 and 6).

Type 3 Corrected Transposition of the Great Vessels (transposition with sinu-atrial inversion; Cardell's B4), one patient (Fig. 7).

As far as we can tell this syndrome also occurs only in association with isolated dextrocardia or isolated lævocardia. The description that follows assumes lævocardia but will also apply to dextrocardia if the sides are reversed. A left-sided superior vena cava and a left-sided inferior vena cava drain into a left-sided venous atrium which has a limbus and fossa ovalis on its septal surface. This atrium communicates with the left-sided morphological left ventricle through a bicuspid atrioventricular valve. This ventricle gives rise to the pulmonary artery which is situated posteriorly and to the left. The pulmonary veins drain into a right-sided arterial atrium, which has on its septal surface the irregular configuration of the septum primum as it is adherent to the septum secundum. This atrium communicates through a tricuspid atrioventricular

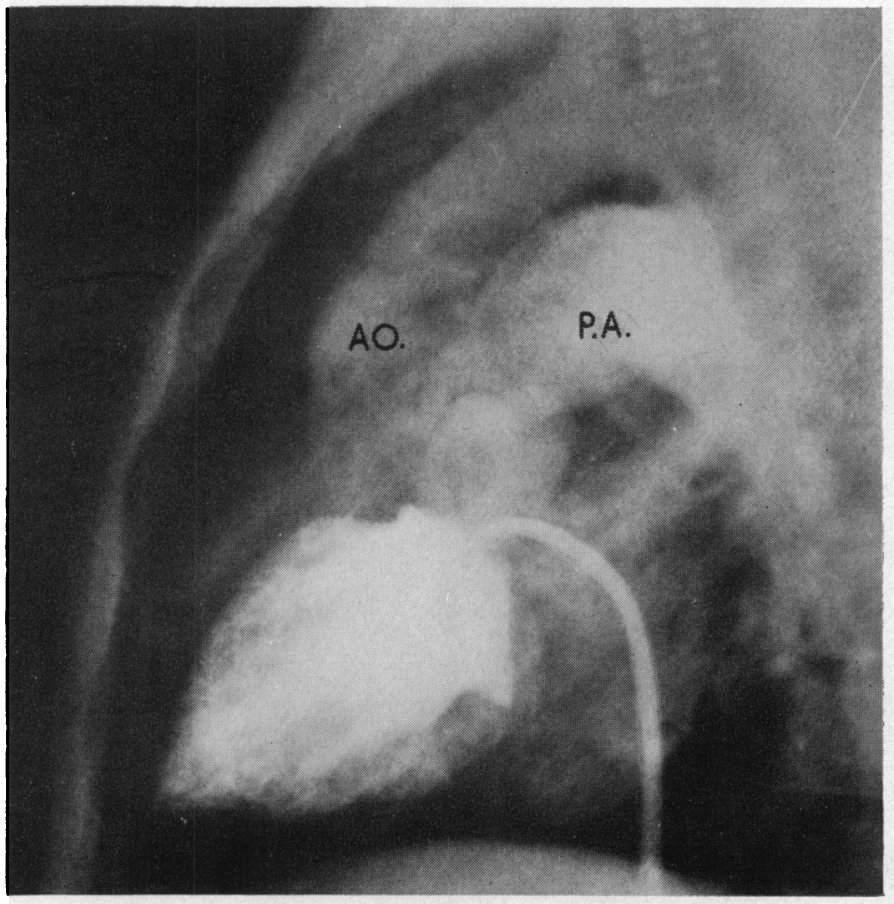

FIG. 5.-Patient 12. Lateral angiocardiography showing transposition of the great vessels. Abbreviations as in Fig. 6 . 
valve with the right-sided morphological right ventricle. This ventricle gives rise to the aorta, which is situated anteriorly and to the right. In our one case and in the reported cases the aortic arch has always been on the side opposite the cardiac apex. The coronary arteries are transposed. The left coronary artery arises from an anterior sinus and courses to the left, dividing into an anterior descending and left circumflex branches. The right coronary artery arises from a posterior aortic sinus and courses to the right, dividing into a posterior descending and right marginal branches. The electrocardiogram shows an inverted $P$ wave in lead $I$, since the atria are inverted. These cases are as liable to develop heart block as the type 1 cases since the relation of the atria to the ventricles is similar in the two groups.

Patient 13 (isolated dextrocardia). A boy, aged 8 years, was noticed to be cyanosed when 2 months old and a murmur was found. He was small for his age, with marked central cyanosis and digital clubbing. The electrocardiogram showed an inverted $\mathbf{P}$ wave in lead $\mathbf{I}$, with the right and left arm leads reversed, and complete heart block. At cine-angiography, the right-sided superior vena cava was seen to enter a right venous atrium. A right-sided ventricle then filled and from this arose an abnormally situated pulmonary artery which ran parallel with the right cardiac border. At the same time, the left-sided arterial ventricle was opacified through a ventricular septal defect and the aorta could be seen, ascending vertically just to the left of, but slightly overlapping, the main pulmonary artery. The aortic arch and descending aorta were left sided.

\section{Discussion}

Corrected transposition of the great vessels with bulbo-ventricular inversion (type 1) is now very well recognized. Its embryology, pathology, and clinical features have been described in great detail in several recent papers. The other two types of corrected transposition have been grouped together and vaguely described in published reports under the title of dextrorotation, dextroversion, or "some type of lævocardia". It is not clear, however, whether these two types have been recognized as two separate entities and whether they have been considered different

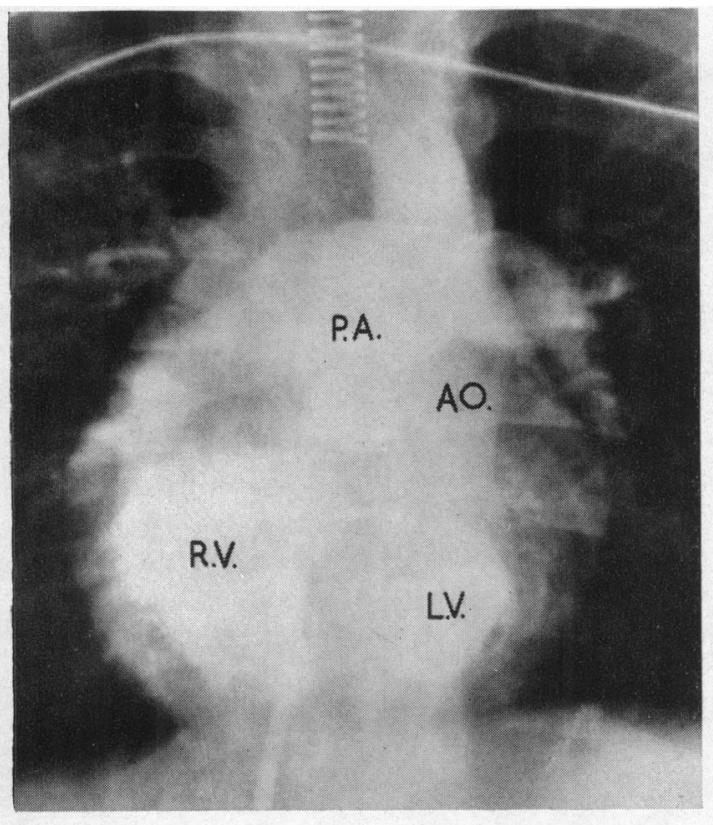

Fig. 6.-Patient 12. Venous angiocardiography showing morphological right ventricle on the right (R.V.) giving rise to pulmonary artery (P.A.), and morphological left ventricle on the left (L.V.) giving rise to aorta (AO). Aortic arch on the left. from type 1. De La Cruz et al. (1959, 1962), classified corrected transposition of the great vessels associated with bulbo-ventricular inversion (type 1) into two groups. Their first group is corrected transposition in a normally situated heart, a division of this being dextrorotation. Their other group is corrected transposition of the great vessels in mirror image dextrocardia and a division of this is "some type of lævocardia". According to these workers, "the atria are normally situated since they are anchored regions of the heart, and are so placed from the very beginning. The location of the anatomical right ventricle in a left-sided position and the anatomical left ventricle in a right-sided position in corrected transposition (with bulboventricular inversion) is a consequence of the type of the bulbo-ventricular loop whose convexity is towards the left and whose concavity is towards the right. The position of the apex to the left can be explained as a failure of the heart to swing to the right, as would be expected for this type of loop. The emergence of the aorta, in front of the crista supraventricularis from the anatomical right ventricle, that of the pulmonary artery from the anatomical left 
ventricle, and the course of the aorta parallel and vertical to the pulmonary trunk are a consequence of the straight character of the truncoconal septum". De La Cruz and her colleagues added that the same embryological fault is also responsible for the production of corrected transposition with dextrorotation, as "the apex of the heart swings to the right, as would be expected with this type of loop. Likewise in corrected transposition in mirror image dextrocardia, if the apex swings to the left, some type of lævocardia results". The anatomical description they gave to dextrorotation or "some type of lævocardia", is obviously that of our type 3, i.e. corrected transposition with sinuatrial inversion. This explanation offered by De La Cruz et al. $(1959,1962)$ would have been much easier to accept, had there not been cases with the typical pattern of corrected transposition with bulbo-ventricular inversion (type 1) occurring in isolated dextrocardia and isolated lævocardia. Our patient 7 (Fig. 8) and Case 5 of Ivemark (1955) are (examples of corrected transposition with bulbo-ventricular inversion (type 1) in isolated dextrocardia and isolated lævocardia respectively. These two cases illustrate the important fact that when corrected transposition with bulbo-ventricular inversion (type 1) occurs in isolated lævocardia or isolated dextrocardia, the atria are normally situated, the ventricles are inverted, while the great vessels show inverted transposition with the aorta occupying the position of the main pulmonary artery. It appears, therefore, that inversion of the atria, with normal position of the ventricles, and complete or crossed transposition of the great vessels are the probable embryological faults responsible for the production of type 3 corrected transposition. This type of corrected transposition, however, is rare. In Cardell's series, there was only one example. Case 11 of Lev and Rowlatt (1961), the case reported by Yater (1929), the two cases of Platzer (1955), and Case 1 of Rosenbaum, Pellegrino, and Treciokas (1962), are all examples of this syndrome in isolated lævocardia and isolated dextrocardia. Heart block will occur as frequently as in type 1 , since the relation of the atria to the ventricles is the same in the two syndromes. Yater's case had complete heart block and the occurrence of this

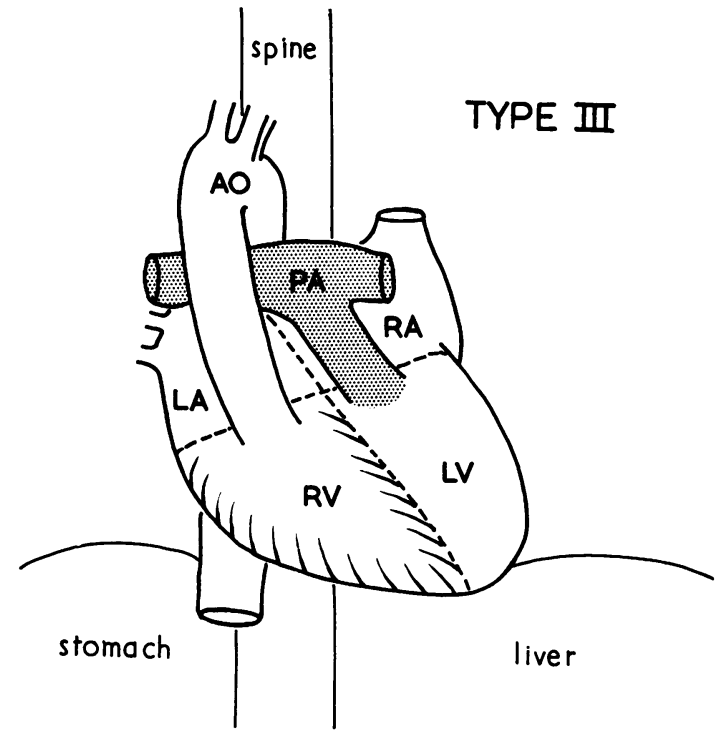

Fig. 7.-Type 3 corrected transposition of the great vessels. Abbreviations as in Fig. 2. Abdominal viscera and atria inverted, but not the ventricles or the position of the heart.

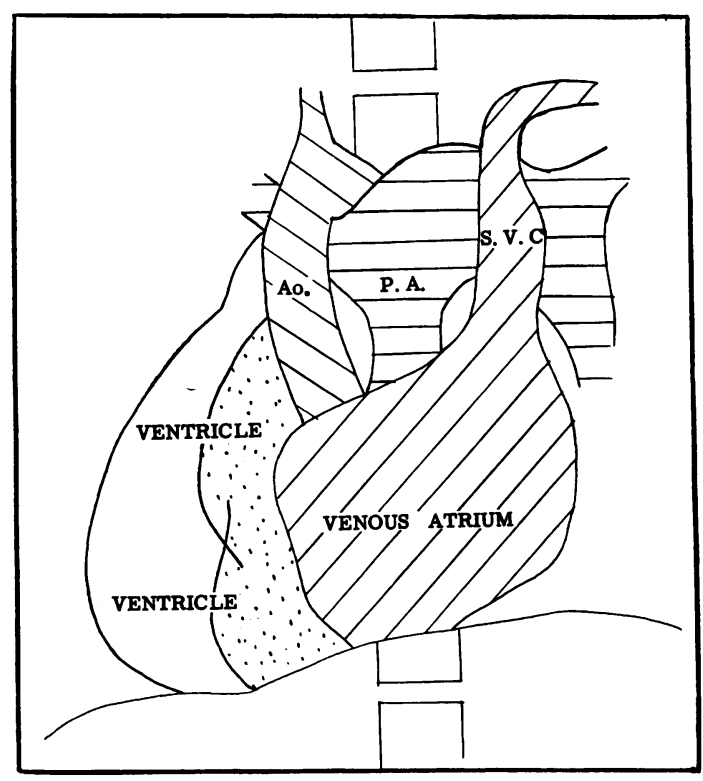

Fig. 8.-Patient 8: direct tracing from venous angiocardiogram, showing left superior vena cava (S.V.C.), venous atrium on the left, and inverted transposition of the great vessels with the aorta (Ao) occupying the normal position of the pulmonary artery (P.A.) at the right cardiac border. 
conduction defect in our Case 13 suggests situs solitus of the ventricles, the atria being shown angiocardiographically to be inverted.

In corrected transposition with atrioventricular inversion (type 2), the atria and the ventricles are inverted together and the great vessels show the anatomy of complete or crossed transposition. All our cases and the published cases had either isolated dextrocardia or isolated lævocardia. The similarity of this syndrome to type 3 is striking, hence the confusion in published material between them. Both occur in isolated dextrocardia and isolated lævocardia, and the aortic arch is always on the side opposite to the cardiac apex. The anatomy of the transposed great vessels is similar in both, the aorta being anterior and to the right of the pulmonary artery (this assumes lævocardia but will also apply to dextrocardia if the sides are reversed). The atria are inverted in both. The ventricles and the atrioventricular valves are inverted in type 2 whereas they are normally situated in type 3 . The transposition is therefore corrected physiologically and anatomically in type 2 but only physiologically in type 3 . The coronary arteries are transposed and inverted in type 2 but only transposed in type 3 . The electrocardiogram usually shows inversion of the $P$ wave in lead $I$ in both, but heart block is not a common feature of type 2, whereas it is a common feature of type 3. But in isolated lævocardia or isolated dextrocardia, the presence of $P$ wave inversion in lead $I$ in the electrocardiogram and the presence of an aortic arch on the side opposite the cardiac apex are not diagnostic of corrected transposition types 2 and 3. Case 2 of Rosenbaum et al. (1962) with isolated lævocardia and Case 1 of Burchell and Pugh (1952) with isolated dextrocardia, had atrial inversion and the aortic arch was on the side opposite to the cardiac apex, but the great vessels were normally situated. Cases described by the following authors are probably examples of type 2 corrected transposition of the great vessels (Grunmach, 1890; Kelsey, Gilmore, and Edwards, 1953; and Case 1 of Hanson and Tabakin, 1961). The case described by Fitzgerald (1960) demonstrates the atrioventricular inversion that occurs in this syndrome: the transposed great vessels, however, were both arising from the morphological left ventricle. The probable embryological fault responsible for corrected transposition type 2 and 3 has been discussed by Shaher and Johnson (1963), who have suggested that while in isolated lævocardia (or isolated dextrocardia if the sides are reversed) the future superior vena cava and the future inferior vena cava are developing on the left, the future venous chambers of the heart are developing on the right. This situation is corrected in a group of cases by variable degrees of rotation of the cardiac tube, atria, ventricles, and bulbus cordis. In corrected transposition types 2 and 3, the atria are inverted, and the ventricles may become inverted (type 2) or develop normally (type 3). Straight development of the trunco-conal septum results in transposition of the great vessels. The main differences between the three types of corrected transposition of the great vessels are illustrated in the Table.

There is one remaining type of corrected transposition that we have not yet commented on. This is Cardell's B1, or transposition associated with bulbar inversion only. Cardell gave references to six cases described in published reports, which he thought were examples of this type (Grunmach, 1890; Théremin, Case 47, 1895; Lewis and Abbott, 1915; Doerr, Case 1, 1939; Carns et al., 1941; Brown, 1950). Cardell defined this type of corrected transposition associated with bulbar inversion as one in which there was both functional and anatomical correction, the aorta arising from the morphological left ventricle and receiving aerated blood. Comparing his diagram B1 illustrating this type of transposition with his diagram of the normal heart, it appears that the features of this syndrome are morphologically right venous chambers on the right giving rise to a pulmonary artery situated posteriorly and to the right, and morphologically left arterial chambers on the left giving rise to an aorta situated anteriorly and to the left, i.e. normally placed cardiac chambers associated with inverted transposition of the great vessels. Each of the six cases referred to by Cardell shared a common feature in having a tricuspid right atrioventricular valve and a bicuspid left atrioventricular valve. The case described by Grunmach (1890) is an example of type 2 corrected transposition in isolated dextrocardia. Théremin's Case 47 (1895) is an example of corrected transposition with bulbo-ventricular inversion (type 1): Théremin described the left ventricle as 
TABLE I

The Syndromes of Corrected Transposition of the Great Vessels

(The description assumes lævocardia, but also applies to dextrocardia if the sides are reversed)

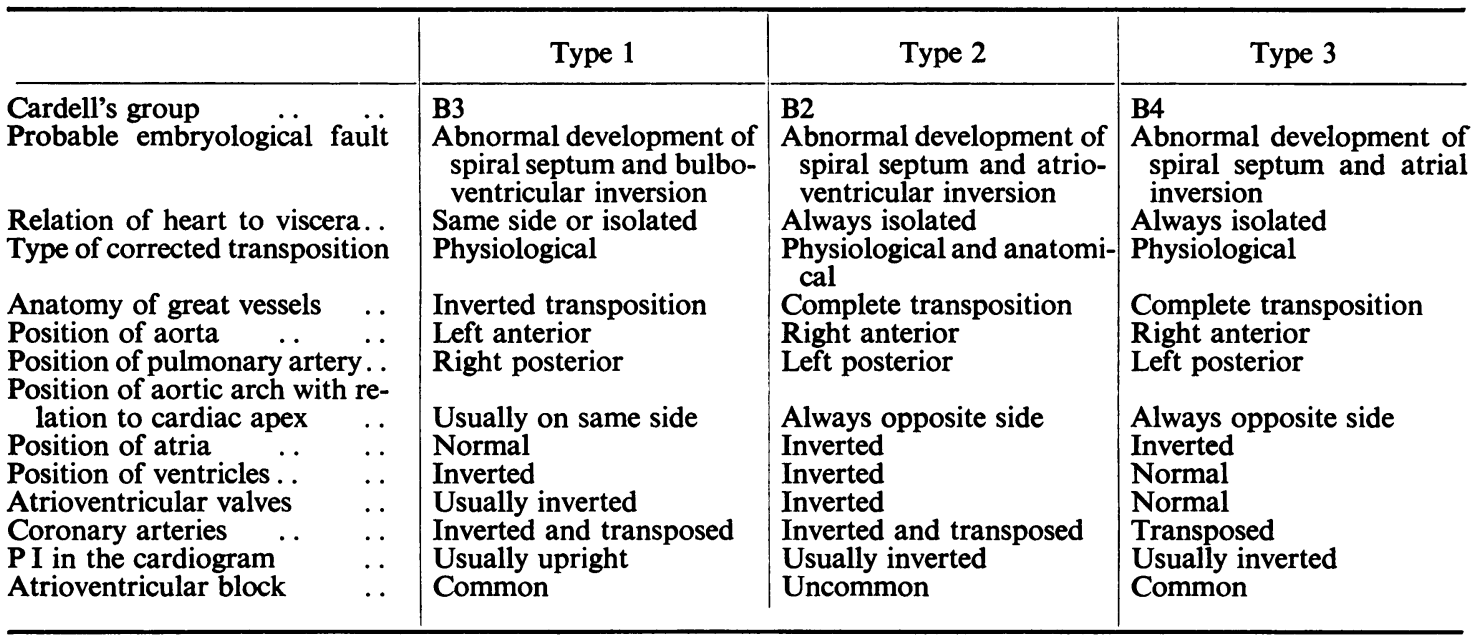

follows "Le ventricule gauche a une valvule bicuspide assez bien formée et devant sa valvule antérieure on trouve une espèce de cone pulmonaire, qui mène dans l'aorte transposée". In Brown's case no detailed anatomy of the topography of the ventricles was given. The other three cases of Lewis and Abbott (1915), Doerr (1939), and Carns et al. (1941), were all examples of single ventricle with inverted transposition of the great vessels. It appears that Cardell accepted a leftsided bicuspid atrioventricular valve as indicating a left-sided morphological left ventricle and a right-sided atrioventricular valve as indicating a right-sided morphological right ventricle. Since we know that absolute identification of the ventricles depends on the topography of the ventricular septum (Lev, 1954), Cardell's conclusion is probably unjustified. Whether corrected transposition associated with bulbar inversion only (Cardell's B1) really exists remains uncertain.

\section{SUMMARY}

Thirteen patients with corrected transposition of the great vessels were seen at Guy's Hospital and at Southampton Chest Hospital. These patients were divided into three types: type 1, with bulbo-ventricular inversion, eight patients; type 2, with atrioventricular inversion, four patients; and type 3, with sinu-atrial inversion, one patient. The main embryological, pathological, and clinical differences between the three types are discussed. The existence of a type of corrected transposition associated with bulbar inversion only is thought to be doubtful.

I am indebted to Dr. D. C. Deuchar and D. H. Davies for helpful criticism, and to Dr. C. G. Baker and D. C. Deuchar for permission to study their patients. I am very grateful to Dr. A. M. Johnson for allowing me to study his patient from Southampton Chest Hospital. I wish to thank Miss D. Healy for her assistance during the preparation of this paper. The work of the Departments of Medical Photography and Medical Illustration is gratefully acknowledged.

\section{REFERENCES}

Anderson, R. C., Lillehei, C. W., and Lester R. G. (1957). Corrected transposition of the great vessels of the heart. Pediatrics, 20, 626.

Beck, W., Schrire, V., Vogelpoel, L., Nellen, M., and Swanepoel, A. (1961). Corrected transposition of the great vessels. Brit. Heart J., 23, 497.

Brown, J. W. (1950). Congenital Heart Disease, 2nd ed. Staples, London.

Burchell, H. B., and Pugh, D. G. (1952). Uncomplicated isolated dextrocardia. Amer. Heart J., 44, 196. 
Campbell, M. (1960). Lævocardia with transposition of abdominal viscera. Brit. Heart J., $22,432$. , and Forgacs, P. (1953). Lævocardia with transposition of the abdominal viscera. Brit. Heart J., $15,401$.

Cardell, B. S. (1956). Corrected transposition of the great vessels. Brit. Heart J., 18, 186.

Carns, M. L., Ritchie, G., and Musser, M. J. (1941). An unusual case of congenital heart disease in a woman who lived for 44 years and six months. Amer. Heart J., $21,522$.

De La Cruz, M. V., Anselmi, G., Cisneros, F., Reinhold, M., Portillo, B., and Espino-Vela, J. (1959). An embryologic explanation for the corrected transposition of the great vessels. Additional description of the main anatomic features of this malformation and its varieties. Amer. Heart J., 57, 104.

- Polansky, B. J., and Novarro-López, F. (1962). The diagnosis of corrected transposition of the great vessels. Brit. Heart J., 24, 483.

Doerr, W. (1939). Zur Transposition der Herzschlagadern. Ein kritischer Beitrag zur Lehre der Transpositionen. Virchows Arch. path. Anat., 303, 168.

Fink, B. W., Adams, F. H., McFall, R. A., and O'Loughlin, B. J. (1958). Corrected transposition of the great vessels associated with intracardiac defects. Pediatrics, $21,381$.

Fitzgerald, M. J. T. (1960). Isolated lævocardia with situs inversus viscerum. Brit. Heart J., $22,429$.

Gasul, B. M., Graettinger, J. S., and Bucheleres, G. (1959). Corrected transposition of the great vessels. Demonstration of a new phonocardiographic sign of this malformation. J. Pediat., 55, 180.

Grant, R. P. (1958). The syndrome of dextroversion of the heart. Circulation, 18, 25.

Grunmach, E. (1890). Ueber angeborene Dexiocardie. Berl. klin. Wschr., 27, 22.

Hanson, J. S., and Tabakin, B. S. (1961). Primary and secondary dextrocardia. Amer. J. Cardiol., 8, 275.

Harley, H. R. S. (1958). The embryology of cor triloculare biatriatum with bulbar (rudimentary) cavity. Guy's Hosp. Rep., 107, 116.

Harris, J. S., and Farber, S. (1939). Transposition of the great cardiac vessels with special reference to the phylogenetic theory of Spitzer. Arch. Path., 28, 427.

Helmholz, H. F., Jr., Daugherty, G. W., and Edwards, J. E. (1956). Congenital "mitral" insufficiency in association with corrected transposition of the great vessels: report of probable clinical case and review of six cases studied pathologically. Proc. Mayo Clin., 31, 82.

Ivemark, B. I. (1955). Implications of agenesis of the spleen on the pathogenesis of cono-truncus anomalies in childhood. Acta paediat. (Uppsala), 44, Suppl. 104.

Keith, J. D., Rowe, R. D., and Vlad, P. (1958). Heart Disease in Infancy and Childhood. Macmillan, New York.

Kelsey, J. R., Jr., Gilmore, C. E., and Edwards, J. E. (1953). Bilateral ductus arteriosus representing persistence of each sixth aortic arch. Arch. Path., 55, 154.

Kernen, J. A. (1958). Corrected transposition of the great vessels of the heart. Amer. Heart J., 56, 583.

Lev, M. (1954). Pathologic diagnosis of positional variations in cardiac chambers in congenital heart disease. Lab. Invest., 3, 71.

- and Rowlatt, U. F. (1961). The pathologic anatomy of mixed levocardia. Amer. J. Cardiol., 8, 216.

Lewis, F. T., and Abbott, M. E. (1915). Reversed torsion of the human heart. Anat. Rec., 9, 103.

Liebow, A. A., and McFarland, W. (1941). "Corrected transposition" and persistent rudimentary "right aorta" as evidence in support of Spitzer's theory. Arch. Path., 32, 356.

Malers, E., Björk, V. O., Cullhed, I., and Lodin, H. (1960). Transposition functionally totally corrected, associated with "mitral" insufficiency. Amer. Heart J., 59, 816.

Mandelstamm, M., and Reinberg, S. (1928). Die Dextrokardie. Klinische, röntgenologische und elektrokardiographische Untersuchungen über ihre verschiedenen Typen. Ergebn. inn. Med. Kinderheilk., 34, 154.

Platzer, W. (1955). Zwei Fälle von Transpositionen mit funkioneller Korrektur. Virchows Arch. path. Anat., 327, 400.

Rokitansky, C. F. von (1875). Die Defecte der Scheidewände des Herzens. Braumüller, Vienna.

Rosenbaum, H. D., Pellegrino, E. D., and Treciokas, L. J. (1962). Acyanotic levocardia. Circulation, $26,60$.

Schaefer, J. A., and Rudolph, L. A. (1957). Corrected transposition of the great vessels. Amer. Heart J., $54,610$.

Shaher, R. M. (1963). Complete and inverted transposition of the great vessels. Brit. Heart J. (In the press).

- and Johnson, A. M. (1963). Isolated lævocardia and isolated dextrocardia. Pathology and pathogenesis. Guy's Hosp. Rep. In the press.

Spitzer, A. (1923). Über den Baulan des normalen und missbildeten Herzens. Versuch einer phylogenetischen Theorie. Virchows Arch. path. Anat., 243, 81. Translated by Lev, M., and Vass, A. (1951). The Architecture of Normal and Malformed Hearts. Thomas, Springfield, Illinois.

Théremin, E. (1895). Etudes sur les affections congénitales du cour. Asselin and Houzeau, Paris.

Yater, W. M. (1929). Congenital heart-block. Amer. J. Dis. Child., 38, 112.

Walmsley, T. (1931). Transposition of the ventricles and the arterial stems. J. Anat. (Lond.), $65,528$. 